Check for updates

Cite this: Phys. Chem. Chem. Phys., 2018, 20, 16817

Received 15th May 2018,

Accepted 4th June 2018

DOI: $10.1039 / c 8 c p 03094 d$

rsc.li/pccp

\section{X-ray-induced sample damage at the Mn L-edge: a case study for soft X-ray spectroscopy of transition metal complexes in solution $\dagger$}

\begin{abstract}
Markus Kubin, (D) a Jan Kern, (D) ${ }^{b}$ Meiyuan Guo, (D) ${ }^{c}$ Erik Källman, ${ }^{c}$ Rolf Mitzner, ${ }^{a}$ Vittal K. Yachandra, ${ }^{\mathrm{b}}$ Marcus Lundberg, (D) ${ }^{\mathrm{c}}$ Junko Yano (D) ${ }^{\mathrm{b}}$ and Philippe Wernet (D) ${ }^{a}$

$X$-ray induced sample damage can impede electronic and structural investigations of radiation-sensitive samples studied with $X$-rays. Here we quantify dose-dependent sample damage to the prototypical $\mathrm{Mn}^{\prime \prime \prime}$ (acac) ${ }_{3}$ complex in solution and at room temperature for the soft $\mathrm{X}$-ray range, using $\mathrm{X}$-ray absorption spectroscopy at the $\mathrm{Mn} \mathrm{L-edge.} \mathrm{We} \mathrm{observe} \mathrm{the} \mathrm{appearance} \mathrm{of} \mathrm{a} \mathrm{reduced} \mathrm{Mn}^{\|}$species as the $\mathrm{X}$-ray dose is increased. We find a half-damage dose of 1.6 MGy and quantify a spectroscopically tolerable dose on the order

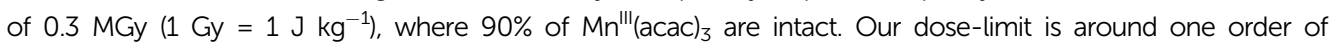
magnitude lower than the Henderson limit (half-damage dose of $20 \mathrm{MGy}$ ) which is commonly employed for protein crystallography with hard X-rays. It is comparable, however, to the dose-limits obtained for collecting un-damaged $\mathrm{Mn}$ K-edge spectra of the photosystem II protein, using hard X-rays. The dose-dependent reduction of $\mathrm{Mn}^{\mathrm{III}}$ observed here for solution samples occurs at a dose limit that is two to four orders of magnitude smaller than the dose limits previously reported for soft X-ray spectroscopy of iron samples in the solid phase. We compare our measured to calculated spectra from ab initio restricted active space (RAS) theory and discuss possible mechanisms for the observed dose-dependent damage of $\mathrm{Mn}^{\prime \prime \prime}$ (acac) 3 in solution. On the basis of our results, we assess the influence of sample damage in other experimental studies with soft X-rays from storage-ring synchrotron radiation sources and X-ray free-electron lasers.
\end{abstract}

\section{Introduction}

$\mathrm{X}$-ray induced damage to radiation-sensitive samples such as (metallo-) proteins in solution is a phenomenon well-known in $\mathrm{X}$-ray crystallography and spectroscopy in the energy range of hard X-rays (1-100 keV), but is less well characterized in X-ray spectroscopic investigations with soft X-rays (0.1-1 keV). X-ray induced sample damage depends on the absorbed X-ray dose $D=E / m$ which is the ratio of absorbed photon energy $E$ and the absorbing mass $m$ of the probed sample volume and it is measured in units of Gray (Gy, where $\left.1 \mathrm{~Gy}=1 \mathrm{~J} \mathrm{~kg}^{-1}\right)$. In X-ray

\footnotetext{
${ }^{a}$ Institute for Methods and Instrumentation for Synchrotron Radiation Research, Helmholtz-Zentrum Berlin für Materialien und Energie GmbH, Albert-Einstein-Str. 15, 12489 Berlin, Germany. E-mail: wernet@helmholtz-berlin.de; Tel: +4930806213448

${ }^{b}$ Molecular Biophysics and Integrated Bioimaging Division, Lawrence Berkeley National Laboratory, Cyclotron Road, Berkeley, CA 94720, USA. E-mail: jyano@lbl.gov; Tel: +1 5104864366

${ }^{c}$ Department of Chemistry - Ångström Laboratory, Uppsala University, SE-75121, Uppsala, Sweden

$\dagger$ Electronic supplementary information (ESI) available: Details on sample preparation; data processing and analysis; diffusion-driven exchange with the sample reservoir; comparison to reference spectra. See DOI: $10.1039 / \mathrm{c} 8 \mathrm{cp} 03094 \mathrm{~d}$
}

protein crystallography with synchrotron radiation sources a typical threshold known as the Henderson limit of 20 MGy $\left(2 \times 10^{7} \mathrm{~Gy}\right)$ was defined, where for protein crystals at cryogenic temperatures half of the diffraction signal is lost due to sample damage. ${ }^{1}$ This limit was more recently refined by Garman et al., to be 30 MGy $\left(3 \times 10^{7} \mathrm{~Gy}\right) .^{2}$

Proposed explanations for this dose-dependent sample damage reflect the creation of electrons and radicals ("electrongain centers" and "electron-loss centers"), initiated by the emission of Auger- and photoelectrons within the sample bulk after absorption of an X-ray photon. These "primary" electrons can scatter multiple times within the sample, creating a local cloud of radicals and "secondary" electrons. ${ }^{4}$ These can subsequently diffuse or tunnel and react, for example, with protein residues and cleave molecular bonds, leading to (irreversible) changes in the local molecular structures. ${ }^{5,6}$ These local changes can disrupt the long-range structure of a protein crystal (order of magnitude of $1 \mathrm{~nm}$ ), explaining the loss of diffraction intensity. Dose-limits for $50 \%$ loss of diffraction intensity are reported between 1 and $40 \mathrm{MGy}$, depending on the experimental conditions such as, in particular, the sample temperature. ${ }^{2,7,8}$

In contrast to X-ray crystallography, X-ray spectroscopic methods based on hard ${ }^{9-11}$ and soft X-rays ${ }^{12-15}$ probe the local 
electronic structure which can be strongly affected by local chemical changes such as changes in bond distances and oxidation states, initiated by reactions with the radicals and electrons that are generated during the measurement. ${ }^{16,17}$ This specific kind of sample damage affects, in particular, high-valent $3 \mathrm{~d}$ transition metals, many of which are relevant for catalytic processes in metalloproteins. X-ray absorption and emission studies of the photosystem II (PS II) protein have shown that high-valent $\mathrm{Mn}^{\text {III }}$ and $\mathrm{Mn}^{\mathrm{IV}}$ ions in the native oxygen evolving complex of PS II are reduced to $\mathrm{Mn}^{\mathrm{II}}$ species upon irradiation with hard X-rays (Mn K-edge at $\sim 6.5 \mathrm{keV}$ ), where $50 \%$ of the $\mathrm{Mn}$ atoms are reduced to $\mathrm{Mn}^{\mathrm{II}}$ at an X-ray dose between $\sim 0.1$ and $\sim 10 \mathrm{MGy}$ (half-damage dose), with a trend to higher dose-limits at cryogenic temperatures, ${ }^{18}$ and lower dose limits at room temperature. ${ }^{19}$

There are only a few studies of dose-dependent sample damage in the soft X-ray regime, mostly reporting damage to samples in the solid phase, with widely varying (half-damage) dose limits between $49 \mathrm{MGy}$ and $4.2 \mathrm{GGy} .{ }^{20,21}$ We are not aware of any comparable work with soft X-rays on transition-metal complexes in solution and at room temperature, relevant for studying metalloproteins under ambient conditions and catalytic processes in solution without the influence of dose-dependent sample damage. ${ }^{22}$ Quantifying these dose limits and unraveling the underlying damage mechanism is expected to provide important information for the design and interpretation of the respective experimental approaches.

Here we bridge this gap with an investigation of dose-dependent sample damage, induced by soft X-rays to the $\mathrm{Mn}^{\mathrm{III}}(\mathrm{acac})_{3}$ complex in solution and at room temperature. We employ X-ray absorption spectroscopy (XAS) at the Mn L-edge to probe the local electronic structure at the Mn center via $2 \mathrm{p}-3 \mathrm{~d}$ transitions. The (high-valent) $\mathrm{Mn}^{\mathrm{III}}$ complex is a valid prototype, as it is sensitive to sample damage and its damage-free L-edge XAS spectrum was characterized previously in solution. ${ }^{15,23}$ We use a static (non-flowing) transmission cell to quantify sample damage to $\mathrm{Mn}^{\mathrm{III}}(\mathrm{acac})_{3}$ by the occurrence of $\mathrm{Mn}^{\mathrm{II}}$ and establish a dose limit above which sample damage starts to severely alter the spectra. We also extract the spectrum of the reduced species $\left(\mathrm{Mn}^{\mathrm{II}}\right)$ and use $a b$ initio calculations based on the restricted active space (RAS) approach ${ }^{24-29}$ to assess possible damage mechanisms. We apply our findings to validate our experimental approaches with liquid jets ${ }^{15,23}$ and start building a basis for the experimental design of damage-free L-edge XAS of transition-metal complexes and metalloproteins in solution, using soft X-rays from storage-ring synchrotron radiation facilities and X-ray free-electron lasers.

\section{Materials and methods}

\section{Sample preparation}

The data reported here is based on two sample preparation methods. Sample A was prepared from solid $\mathrm{Mn}^{\mathrm{III}}(\mathrm{acac})_{3}$ (manganese( $3+$ ) tris[(2Z)-4-oxo-2-penten-2-olate]), acetylacetonato ligands are abbreviated as (acac) ${ }^{-}$, purchased as a crystalline powder (technical grade) from Sigma-Aldrich and dissolved in acetylacetone (Sigma-Aldrich) with concentrations between 100 and $150 \mathrm{mM}$. Sample B was prepared from $\mathrm{Mn}^{\mathrm{II}}(\mathrm{acac})_{2}$ (manganese(2+) bis[(2Z)-4-oxo-2-penten-2-olate $]$ ), purchased as a crystalline powder (technical grade) from SigmaAldrich and dissolved in acetylacetone (Sigma-Aldrich), with concentrations on the order of $50 \mathrm{mM}$. We find that upon solubilizing $\mathrm{Mn}^{\mathrm{II}}(\mathrm{acac})_{2}$ in acetylacetone, the complex undergoes chemical changes that result in an L-edge absorption spectrum similar to that of $\mathrm{Mn}^{\mathrm{III}}(\mathrm{acac})_{3}$ (see Fig. S1 and Section 1 of the ESI $\dagger$ ).

\section{Experimental setup and data analysis}

X-ray absorption spectra of the solution samples were measured in transmission mode with the transmission NEXAFS endstation $^{30}$ at the undulator beamline UE52_SGM ${ }^{31}$ of the BESSY II synchrotron radiation facility. Solution samples were prepared in a transmission cell consisting of a holder with two X-ray transparent $100 \mathrm{~nm}$ thin $\mathrm{Si}_{3} \mathrm{~N}_{4}$ membranes (purchased from Si-Mat Silicon Materials, Germany, membrane area $500 \times 500 \mu \mathrm{m}^{2}$ ). The thickness of the sample (excluding the membranes) varied between 1 and $6 \mu \mathrm{m}$ and was adjusted by varying the pressure of the helium atmosphere in the experimental chamber between 780 and 1000 mbar. The experimental chamber was separated from the beamline vacuum by an additional $150 \mathrm{~nm}$ thin $\mathrm{Si}_{3} \mathrm{~N}_{4}$ membrane. The cell and in particular the sample thickness was monitored as described in ref. 30. The size of the X-ray beam on the sample was determined to be $100 \times 50 \mu \mathrm{m}^{2}$ (horizontal $\times$ vertical), using knife-edge scans. A monochromator slit size of $20 \mu \mathrm{m}$ was used, corresponding to a bandwidth of $50 \mathrm{meV}$ (fwhm).

The photon flux $\Phi_{\mathrm{L}}(h \nu)$ after transmission through the solution sample of thickness $\mathrm{L}$ (plus the two $100 \mathrm{~nm} \mathrm{Si}_{3} \mathrm{~N}_{4}$ membranes and the $\mathrm{He}$ atmosphere with distances in the experimental chamber of $290 \mathrm{~mm}$ before and $45 \mathrm{~mm}$ after the transmission cell) was measured with a calibrated photodiode (Hamamatsu G1127-04 2K, placed on the X-ray beam axis $45 \mathrm{~mm}$ behind the transmission cell). The diode signal was read out by a Keithley Electrometer (model 6514B) and recorded as a function of the incident photon energy $h \nu$ as scanned with the beamline monochromator. Reference spectra $\Phi_{0}(h \nu)$ were recorded under equivalent conditions as the sample scans $\Phi_{\mathrm{L}}(h \nu)$ but on an empty transmission cell equivalent to the sample cell, both mounted on the same holder in the chamber. All diode signals were normalized by the storage ring current of the BESSY II synchrotron radiation facility and single outlier data points (on average four per single-scan) were corrected following the same procedure as in ref. 15. Each scan was taken in steps of $0.1 \mathrm{eV}$ with $1 \mathrm{~s}$ integration time per step resulting in total acquisition times on the order of $10 \mathrm{~min}$ per single scan. Transmission spectra were obtained from the ratio $T_{\mathrm{L}}(h \nu)=$ $\Phi_{\mathrm{L}}(h \nu) / \Phi_{0}(h \nu)$ of single scans $\Phi_{\mathrm{L}}(h \nu)$ with sample and reference scans $\Phi_{0}(h \nu)$ without sample in the transmission cells.

The sample thickness $L$ was determined separately for each scan by fitting the transmission of the pure solvent, as calculated from Henke's tables ${ }^{32,33}$ and using Beer-Lambert's law, to experimental data in the non-resonant spectral ranges $(h \nu \leq 637 \mathrm{eV}$ and $h \nu \geq 654.5 \mathrm{eV}$ ). We estimate the uncertainty of the sample thickness by extracting a minimum and a maximum value from two separate fits at the low-energy ( $h \nu \leq 637 \mathrm{eV}$ ) and the highenergy sides $(h \nu \geq 654.5 \mathrm{eV})$ of each transmission spectrum 
(thereby accounting for differences in the thickness at the beginning and at the end of the scan; see Fig. S2, ESI $\dagger$ ).

Absorption spectra in units of the linear absorption coefficient $\alpha(h \nu)$ were calculated from the transmission spectra via $\alpha_{\text {tot }}(h \nu)=$ $-\ln \left[T_{\mathrm{L}}(h \nu)\right] / L$. Each Mn L-edge absorption spectrum $\alpha_{\mathrm{Mn}}(h \nu)$ was obtained from $\alpha_{\text {tot }}$ after correction for an absorption background $\alpha_{\mathrm{bg}}$ due to the solvent and due to slow drifts in the sample thickness by subtracting a low-order polynomial $\alpha_{\mathrm{bg}}(h \nu)$ (1st and 2nd order). This polynomial was fitted to the non-resonant parts at the low- and the high-energy sides of the spectrum $(h \nu \leq 637 \mathrm{eV}$ and $h \nu \geq 654.5 \mathrm{eV}$ ) and was subtracted from the total absorption signal, so that $\alpha_{\mathrm{Mn}}=\left(\alpha_{\mathrm{tot}}-\alpha_{\mathrm{bg}}\right)$. With this, we neglect information about the magnitude of the edge-jump (absorption beyond the $\mathrm{L}_{2}$-edge), which is acceptable for the purpose of this study and makes the resulting spectra comparable to our previous work. ${ }^{15}$

The axis of incident photon energy was calibrated as previously, ${ }^{15,22,23}$ by applying the same constant energy shift to all spectra in order to match the $\mathrm{L}_{3}$-edge maximum of intact $\mathrm{Mn}^{\mathrm{III}}(\mathrm{acac})_{3}$ sample with the maximum at $641.6 \mathrm{eV}$ of the calibrated spectrum in ref. 15 .

\section{Calculation of absorbed X-ray doses}

The dose $D$ accumulated by the sample was calculated for all single-scan spectra at each data point by integrating over differential doses $\mathrm{d} D$

$$
\begin{aligned}
D & =\int \mathrm{d} D \\
& =\int[1-\exp (-L / \Lambda(h v))] \cdot\left[h \nu \cdot \Phi_{\text {sample }}(h \nu) /(\rho \cdot L \cdot A)\right] \cdot \mathrm{d} t
\end{aligned}
$$

over all scans on the sample, where $h \nu\left(\sim 10^{-16} \mathrm{~J}\right)$ is the photon energy, $\mathrm{d} t(\sim 1 \mathrm{~s})$ is the collection time per data point, $L(\sim 1$ to $6 \mu \mathrm{m}$ ) is the fitted sample thickness (only the solution), $\rho=0.98 \mathrm{~g} \mathrm{~cm}^{-3}$ is the density of the solvent, $A=500 \times$ $500 \mu \mathrm{m}^{2}$ is the surface area of the sample volume and $\Lambda(h \nu)$ $(\sim 1.14 \mu \mathrm{m}$ at a photon energy of $640 \mathrm{eV})$ is the attenuation length of the solvent acetylacetone as obtained from Henke's tables. $^{32,33}$ The flux incident on the sample, $\Phi_{\text {sample }}(h \nu)$, is calculated from $\Phi_{\text {sample }}(h \nu)=\Phi_{0}(h \nu) /\left[T_{\mathrm{He}} \cdot T_{\mathrm{Si}_{3} \mathrm{~N}_{4}}\right]$ with the flux measured with an empty reference cell, $\Phi_{0}(h \nu)$, after correction for the transmission $T_{\mathrm{He}}$ of $45 \mathrm{~mm}$ He atmosphere at a pressure $p(\mathrm{He})$ and for the transmission $T_{\mathrm{Si}_{3} \mathrm{~N}_{4}}$ of one $100 \mathrm{~nm} \mathrm{Si}_{3} \mathrm{~N}_{4}$ cell membrane. Both transmission curves $T_{\mathrm{He}}$ and $T_{\mathrm{Si}_{3} \mathrm{~N}_{4}}$ were calculated from Henke's tables. ${ }^{32,33}$

We emphasize that all doses are calculated with respect to the mass of the full transmission cell volume $V=L \cdot A$. With this, we assume that during a scan (10 min) diffusion evenly distributes reduced $\mathrm{Mn}^{\mathrm{II}}$ species over the volume of the transmission cell. This is justified by estimating the diffusion length of the reduced $\mathrm{Mn}^{\mathrm{II}}$ species in the liquid sample. For two-dimensional diffusion along the plane of the transmission cell, ${ }^{34}$ and using the diffusion coefficient reported for $\mathrm{Mn}^{\mathrm{III}}(\mathrm{acac})_{3}$ in solution, $D_{\text {diff }} \sim 4 \times 10^{-6} \mathrm{~cm}^{2} \mathrm{~s}^{-1,35}$ we estimate a diffusion length of $\lambda=\sqrt{4 t D_{\text {diff }}} \sim 1000 \mu \mathrm{m}$ for the duration of a single scan $(t=10 \mathrm{~min})$. This length is comparable to the dimensions spanned by the transmission cell $\left(500 \times 500 \mu \mathrm{m}^{2}\right)$ and justifies our choice of the reference volume for calculating the dose. We note, however, that we systematically neglect diffusion-driven sample exchange with the reservoir surrounding the transmission cells (with extensions of several millimeters, see Fig. S3a in the ESI $\dagger$ and ref. 30), which occur on longer time scales of around $1 \mathrm{~h}$ (see Fig. S3b, ESI $\dagger$ ). This is taken into account in the discussion of our results. We note also that under the conditions used here we do not have evidence for or against the formation or accumulation of photoproducts on the $\mathrm{Si}_{3} \mathrm{~N}_{4}$ membranes.

As the accumulated dose increases with continuous X-ray illumination during each scan, assigning a distinct dose value to a given spectrum is not possible. We here assign scan-averaged doses and consider the range of doses surpassed during a scan (637-654.5 eV) as the systematic uncertainty. Combined with the thickness variations, these minimum-to-maximum uncertainties are represented by the error bars of the average doses.

\section{Restricted active space (RAS) calculations}

Spectra calculated with the RAS approach were performed with MOLCAS $7.9^{36}$ at the RASPT2/ANO-RCC-VDZP level. ${ }^{23,27}$ The RAS calculations are based on molecular geometries obtained from DFT/B3LYP solvent optimization. As previously, to save computational cost, calculations for the tris-acetylacetonato species were performed on truncated structures where six terminal methyl groups were replaced by hydrogen atoms. We checked that this does not notably change the spectrum. Equivalent geometries were also used for the RAS calculations in ref. 15 and 23. A minimal valence active space consisting of the five metal-3d dominated orbitals were placed in the RAS2 space. The Mn 2p orbitals were placed in the RAS3 space and to ensure the hole stayed in these orbitals they were frozen in the RASSCF optimizations. For the final states, all possible configurations with one core hole were included. RASPT2 calculations were performed using the default ionization potential electron affinity (IPEA) shift of 0.25 Hartree. An imaginary shift of 0.1 Hartree was used to reduce the occurrence of "intruder states" in the core-excited states. Effects of model choices on spectral shape have been analyzed in ref. 37 . All calculations were performed in a solvent environment that was modeled using the polarized continuum model (PCM) for the solvent acetylacetone. For comparison to the calculated spectra in ref. 15 we checked that changing the solvent from acetylacetone to ethanol has no effect on the calculated L-edge spectra. RAS spectra were broadened with a Gaussian with $0.3 \mathrm{eV}$ fwhm and Lorentzian lifetime widths $0.2 \mathrm{eV}$ and $0.7 \mathrm{eV}$ (fwhm) for the $\mathrm{L}_{3}$ and $\mathrm{L}_{2}$-edges, respectively. ${ }^{38}$ The energy axis of all calculated spectra was corrected by a constant shift of $-4.94 \mathrm{eV}$ as determined previously for coinciding $\mathrm{L}_{3}$-edge peak maxima in experimental and calculated VDZP-quality spectra of $\mathrm{Mn}^{\mathrm{II}}(\mathrm{acac})_{2}{ }^{23}$

\section{Results and discussion}

\section{Experimental setup}

The experimental setup ${ }^{30}$ used for studying X-ray induced damage to $\mathrm{Mn}^{\mathrm{III}}(\mathrm{acac})_{3}$ solution samples with transmissiondetected XAS is shown in Fig. 1a. The liquid sample is placed in 
a cell with $\mathrm{Si}_{3} \mathrm{~N}_{4}$ membrane windows with a photodiode behind the cell which detects the transmitted intensity of the soft X-ray beam (normal incidence on the sample). The sample cell is used in a non-flowing operation mode which allows for the controlled accumulation of X-ray dose in the liquid sample for successive scans. The structure of the $\mathrm{Mn}^{\mathrm{III}}$ (acac) ${ }_{3}$ complex is shown in Fig. $1 \mathrm{~b}$. The central high-spin $\mathrm{Mn}^{\mathrm{III}}$ atom is coordinated by six oxygen atoms from the acetylacetonato ligands in a nearly octahedral Jahn-Teller distorted symmetry. ${ }^{15,23}$ For analyzing the changes in the spectra as a function of increasing X-ray dose, we used two different beamline settings; setting 1 with $10^{2}$ times reduced flux and setting 2 with $10^{5}$ times reduced X-ray flux, as compared to the typical maximum flux of the X-ray undulator beamline. Measured flux on the sample is compared in Fig. 1c for the energy range relevant to Mn L-edge XAS (for details on the determination of $\Phi_{\text {sample, see the }}$ Methods section). The typical maximum flux available for optimized undulator settings for the beamline is on the order of $10^{12}$ photons $\mathrm{s}^{-1} \cdot{ }^{15}$ In setting 1 , the flux on the sample was on the order of $10^{10}$ photons $\mathrm{s}^{-1}$. This was achieved as follows: by closing the beamline aperture ("beamline baffles") between the monochromator and the refocusing optics to $600 \mu \mathrm{m}$ (reduction factor $\sim 4$ ), closing the monochromator slit to $20 \mu \mathrm{m}$ (reduction factor $\sim 5$ relative to ref. 15 ), and a reduction by $4-5$ with respect to the full flux used in ref. 29 due to the attenuation by $290 \mathrm{~mm} \mathrm{He}$ atmosphere at 750-1000 mbar in the experimental chamber and the $200 \mathrm{~nm} \mathrm{Si}_{3} \mathrm{~N}_{4}$ windows (calculated from Henke's tables ${ }^{32,33}$ ). In setting 1 , the undulator was used in its optimized configuration, i.e. it was set up to follow the monochromator energy during a scan (undulator gap varying between $28.0 \mathrm{~mm}$ and $28.5 \mathrm{~mm}$ with monochromator energies 635-660 eV). In setting 2, we achieved a further reduction (by a factor 1000) to $10^{7}$ photons $\mathrm{s}^{-1}$ by additionally detuning the undulator from this optimized configuration to a static gap distance of $29.4 \mathrm{~mm}$. With this choice we took care to obtain a flat flux profile as a function of photon energy (Fig. 1c) as the X-ray photons originated from the spectrally flat wings of the undulator harmonics.

\section{Damage to $\mathrm{Mn}^{\mathrm{III}}(\text { acac) })_{3}$ by soft X-rays}

In Fig. 2a we compare two consecutive single-scan Mn L-edge XAS spectra of $\sim 150 \mathrm{mM} \mathrm{Mn}^{\mathrm{III}}$ (acac) $)_{3}$ in acetylacetone solution (sample A). Both spectra were recorded at flux setting 1 with $\sim 10^{10}$ photons $\mathrm{s}^{-1}$ on the same sample and the "low-dose" spectrum (first scan) was measured prior to the "high-dose" spectrum (second scan). The absorption spectra are shown in units of linear absorption coefficients $\alpha_{\mathrm{Mn}}$ and are obtained from the raw transmission spectra as described in the Methods section. The thickness of the low-dose spectrum (measured in the center of the cell window) was determined to be between $5.8 \mu \mathrm{m}$ and $6.1 \mu \mathrm{m}$ (see Methods section and Fig. S2 in the ESI $\dagger$ ) and that of the high-dose spectrum (measured closer to the edge of the cell window) was determined to be close to $2.6 \mu \mathrm{m}$. The linear absorption coefficients $\alpha_{\mathrm{Mn}}$ of this $\sim 150 \mathrm{mM}$ sample have peak values on the order of $600 \mu^{-1}$ to $800 \mu \mathrm{m}^{-1}$ which is consistent with our value of around $450 \mu \mathrm{m}^{-1}$ reported for $100 \mathrm{mM}$ damage-free $\mathrm{Mn}^{\mathrm{III}}(\text { acac })_{3}$ in ref. 15 .

The shapes of the high-dose and low-dose spectra differ significantly in the $\mathrm{L}_{3}$ edge, in particular, by the sharp absorption maximum at $639.6 \mathrm{eV}$ in the high-dose spectrum. Comparison to our previously reported Mn L-edge XAS spectra of $\mathrm{Mn}^{\mathrm{II}}(\mathrm{acac})_{2}$ and $\mathrm{Mn}^{\mathrm{III}}(\mathrm{acac})_{3}$ in solution that were free of X-ray induced damage (this assessment is validated in a later section of this paper), ${ }^{15}$ clearly shows that this sharp peak is due to a reduced $\mathrm{Mn}^{\mathrm{II}}$ species, occurring in the sample. The low-dose spectrum is almost identical to the damage-free spectrum of $\mathrm{Mn}^{\mathrm{III}}$ (acac) ${ }_{3}$ as shown by the direct comparison in Fig. 2b. Below $640 \mathrm{eV}$ the high-dose spectrum with its sharp absorption peak maximum at $639.6 \mathrm{eV}$ and the smaller peak at $638.5 \mathrm{eV}$ is similar to the characteristic L-edge XAS spectrum of $\mathrm{Mn}^{\mathrm{II}}$ species such as in $\mathrm{Mn}^{\mathrm{II}}(\mathrm{acac})_{2}$ and $\left[\mathrm{Mn}^{\mathrm{II}}\left(\mathrm{H}_{2} \mathrm{O}\right)_{6}\right]^{2+} \cdot{ }^{15,39}$ These observations clearly show that the spectrum measured at the lower dose is almost free from X-ray induced damage, whereas the spectrum measured at the higher dose contains portions of reduced, spectrally distinct $\mathrm{Mn}^{\mathrm{II}}$ species. This is consistent with observations from Mn K-edge XAS on the PS II protein, where the reduction of high-valent $\mathrm{Mn}^{\mathrm{III}}$ and $\mathrm{Mn}^{\mathrm{IV}}$ sites to spectrally distinct, reduced $\mathrm{Mn}^{\mathrm{II}}$ species is observed for increasing X-ray doses. ${ }^{18}$ A similar effect was reported for Fe L-edge XAS with the dose-dependent reduction of $\mathrm{Fe}^{\mathrm{III}}$ to $\mathrm{Fe}^{\mathrm{II}}$ compounds. ${ }^{21,40}$

Starting from this qualitative picture of dose-dependent reduction of $\mathrm{Mn}^{\mathrm{III}}$ to $\mathrm{Mn}^{\mathrm{II}}$ in $\mathrm{Mn}^{\mathrm{III}}(\mathrm{acac})_{3}$, we now aim for systematically quantifying the doses and the amounts of damaged species. In Fig. 2c, we show the accumulated dose, calculated for each data point in the spectra in Fig. 2a and increasing with X-ray irradiation a

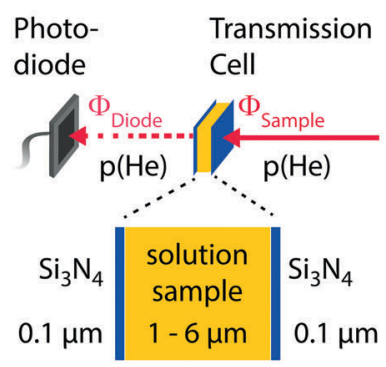

b

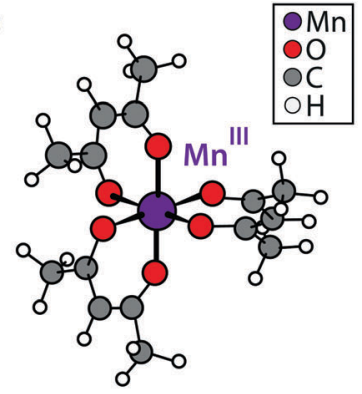

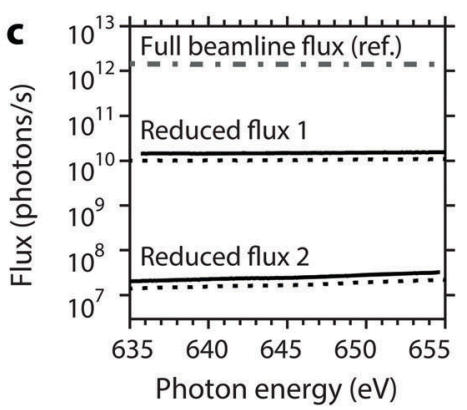

Fig. 1 (a) Schematic of the transmission-cell setup (ref. 30) for X-ray absorption spectroscopy at the L-edge of Mn'"(acac) 3 in solution. (b) Molecular structure of $\mathrm{Mn}^{\prime \prime \prime}(\mathrm{acac})_{3}$ (cartoon based on the optimized structure used in ref. 15 and 23). (c) Experimental photon flux for different configurations of the undulator beamline UE52_SGM at the BESSY II synchrotron (solid: sample A; dotted: sample B) as compared to the full beamline flux (dash-dotted) from ref. 15. 


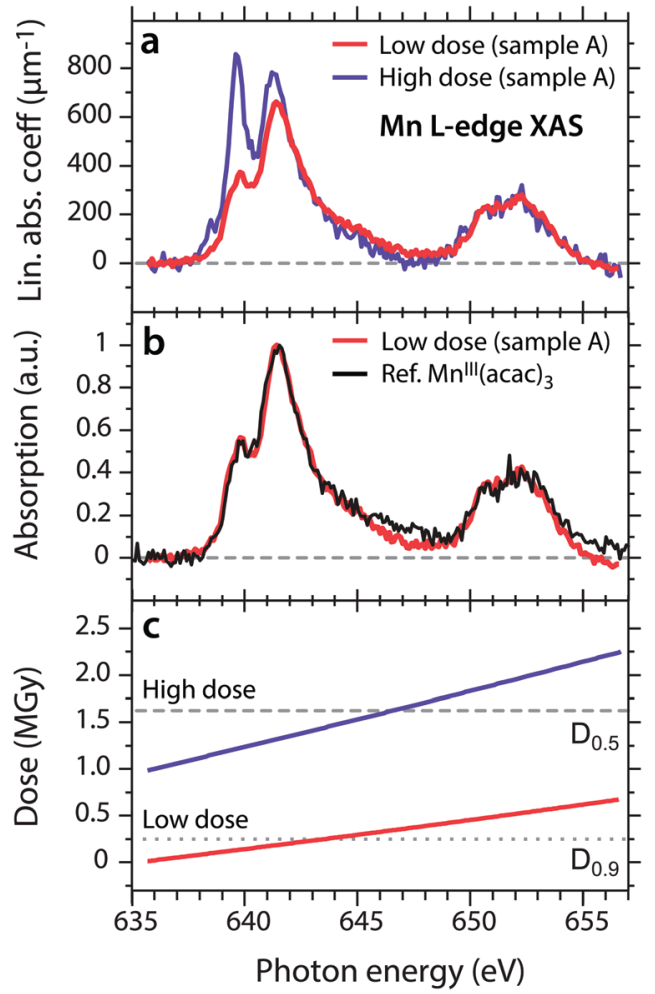

Fig. 2 (a) Two subsequent scans of the same sample of $\mathrm{Mn}^{\prime \prime \prime}(\mathrm{acac})_{3}$ in acetylacetone solution measured with the reduced flux setting 1 (see Fig. 1c), here shown in units of the linear absorption coefficient $\alpha_{\text {Mn }}$ (see Methods section). (b) Comparison of the spectrum measured at low dose from (a) to that of damage-free $\mathrm{Mn}^{\prime \prime \prime}(\mathrm{acac})_{3}$ in ethanol (black), taken from ref. 15. Spectra are normalized to one at maximum. (c) X-ray dose accumulated by the sample volume, as calculated for each data point of the low-dose and the high-dose scans in (a). Doses are calculated with respect to the volume of the transmission cell with an area of $500 \times$ $500 \mu \mathrm{m}^{2}$ and thicknesses on the order of $6 \mu \mathrm{m}$ (low dose, red) and $3 \mu \mathrm{m}$ (high dose, purple).

time. We note that, while the scan of the low-dose spectrum starts at a dose of around 0 MGy, the scan of the high-dose spectrum starts at around 1 MGy due to the dose accumulated during the preceding scan. The average dose (see Methods section) calculated for the two spectra in Fig. $2 \mathrm{a}$ is $0.33 \pm 0.28 \mathrm{MGy}$ and $1.6 \pm 0.6 \mathrm{MGy}$, respectively.

The general observations made here for the low- and highdose spectra are also observed for low and high doses in the series of spectra shown in Fig. 3. Here we show consecutive scans of Mn L-edge XAS spectra of $\mathrm{Mn}^{\mathrm{III}}(\mathrm{acac})_{3}$ in solution of samples A (spectra "a", "b", "d", "f") and sample B (spectra "c", "e", "g", "h"), sorted by average dose from bottom to top. Spectra "a", "b" and "c" were scanned with flux setting 2 ( $\sim 10^{7}$ photons s ${ }^{-1}$ on sample, diode currents $\left.\sim 30-140 \mathrm{pA}\right)$ at an average dose on the order of kGy (spectra at these low diode currents are affected by slow drifts and sudden jumps; spectrum "c" is corrupted for $\geq 649 \mathrm{eV}$ due to an unintentional change of the dynamic range in the Keithley electrometer). These spectra agree with the undamaged spectrum of $\mathrm{Mn}^{\mathrm{III}}(\mathrm{acac})_{3}{ }^{15}$ Spectra "d" to " $\mathrm{h}$ " were scanned with flux setting $1\left(\sim 10^{10}\right.$ photons s ${ }^{-1}$ on sample, diode currents 1-20 nA) and spectra "e" to "h" (with average doses $\geq 1.4 \mathrm{MGy}$ ) are similar to the damaged highdose spectrum in Fig. 2a.

Fig. 4 illustrates how we further quantify the amount of the reduced $\mathrm{Mn}^{\mathrm{II}}$ species in the sample, using the examples of the low- and high-dose spectra from Fig. 2. Our approach is a leastsquares fit of a linear combination of damage-free spectra of $\mathrm{Mn}^{\mathrm{II}}(\mathrm{acac})_{2}$ and $\mathrm{Mn}^{\mathrm{III}}(\mathrm{acac})_{3}$ taken from ref. 15. In these fits the ratio of integrated absolute absorption cross sections of the $\mathrm{Mn}^{\mathrm{III}}(\mathrm{acac})_{3}$ and $\mathrm{Mn}^{\mathrm{II}}(\mathrm{acac})_{2}$ spectra of $1.16 \pm 0.28$ is maintained and the relative uncertainty of this way of determining the $\mathrm{Mn}^{\mathrm{II}} / \mathrm{Mn}^{\mathrm{III}}$ ratio governs the uncertainty of this fit. Within this approach, the fit curves in Fig. $4 \mathrm{a}$ and $\mathrm{b}$ reveal portions of $5 \% \mathrm{Mn}^{\mathrm{II}}$ $\left(95 \% \mathrm{Mn}^{\mathrm{III}}(\mathrm{acac})_{3}\right)$ for the low-dose spectrum and $53 \% \mathrm{Mn}^{\mathrm{II}}(47 \%$ $\left.\mathrm{Mn}^{\mathrm{III}}(\mathrm{acac})_{3}\right)$ for the high-dose spectrum, both being in good agreement with the experimental spectra (see the small residuals of below $10 \%$ in the bottom panels of Fig. $4 a$ and b, except for the mismatch at $641.6 \mathrm{eV}$ in the high-dose spectrum). This also justifies using $\mathrm{Mn}^{\mathrm{II}}(\mathrm{acac})_{2}$ as a model spectrum for the reduced $\mathrm{Mn}^{\mathrm{II}}$ species (within the uncertainties of our approach we find the same $\mathrm{Mn}^{\mathrm{II}} / \mathrm{Mn}^{\mathrm{III}}$ ratios and comparably good fits when using $\mathrm{Mn}_{\mathrm{aq}}^{\mathrm{II}}{ }^{39}$ as a model for the reduced $\mathrm{Mn}^{\mathrm{II}}$ species ${ }^{39,41}$ ). This analysis was applied to all spectra shown in Fig. 3, with generally good agreement of the fits with the spectra measured at flux setting 1 . Due to the poorer data quality of the spectra measured at flux setting 2 the fit of these spectra includes an additional estimated uncertainty of $30 \%$.

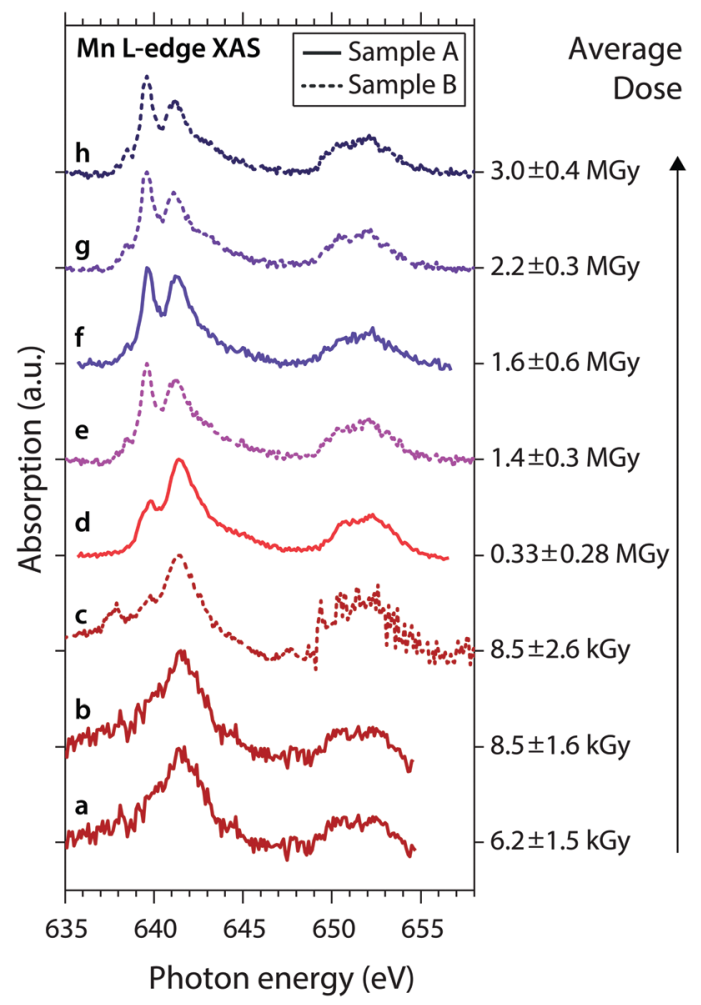

Fig. 3 Series of experimental $\mathrm{Mn} \mathrm{L-edge} \mathrm{absorption} \mathrm{spectra} \mathrm{of} \mathrm{Mn}^{\text {III }(\mathrm{acac})_{3}}$ solution samples A (solid) and B (dotted) with given average doses (error bars reflect the uncertainty of the sample thickness and the range of doses surpassed during a scan). Spectra (a) to (h) are sorted by the average dose values, spectra $(d)$ and $(f)$ are identical to the low-dose and high-dose spectra in Fig. 2a. 

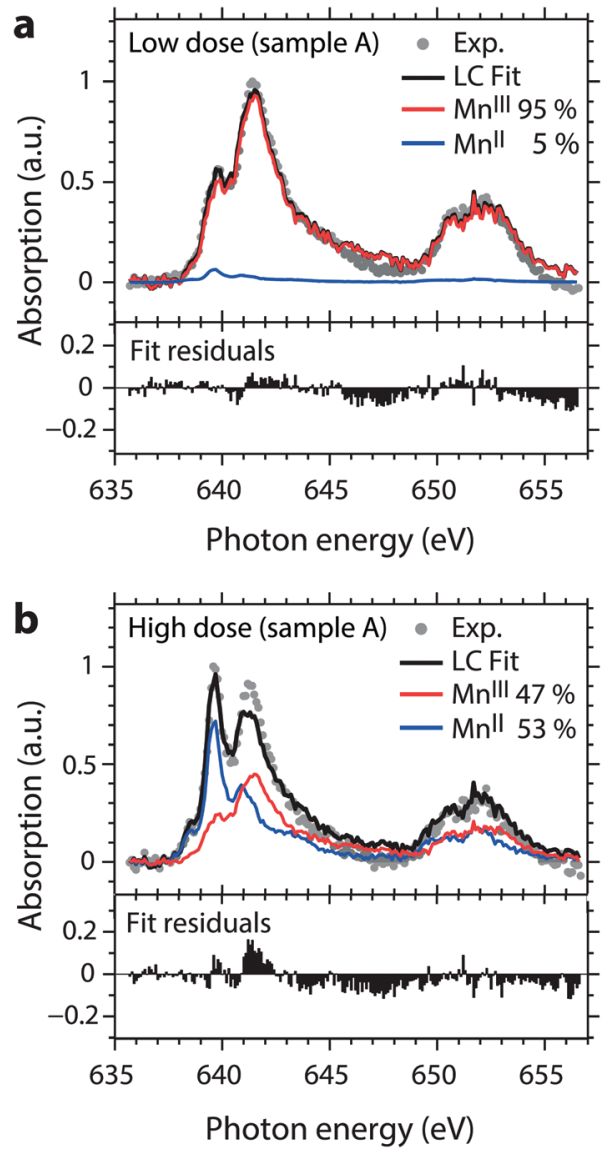

Fig. 4 Fits (black) of normalized low-dose (a) and high-dose (b) absorption spectra (circles, taken from Fig. 2a) with linear combinations of damage-free spectra of $\mathrm{Mn}^{\prime \prime}(\mathrm{acac})_{2}$ (blue) and $\mathrm{Mn}^{\text {III }}(\mathrm{acac})_{3}$ (red) from ref. 15. Fit residuals are shown in the bottom panels.

We note that a spectrum of $\mathrm{Mn}^{\mathrm{III}}(\mathrm{acac})_{3}$ reported in the literature has a similar spectral shape as the spectra of the damaged complex reported here. The $\mathrm{Mn}^{\mathrm{III}}(\mathrm{acac})_{3}$ spectrum reported in ref. 42 is similar to our "high-dose" spectrum at $\sim 1.6$ MGy (Fig. 3). In Fig. S4a in the ESI $\dagger$ we show a leastsquares fit (similar to the fits shown in Fig. 4) to this spectrum and find an amount of roughly $40 \%$ of $\mathrm{Mn}^{\mathrm{II}}$. Building theoretical analyses on this or other spectra of damaged species may consequently lead to erroneous choices of free parameters in the calculations and hence to biased conclusions about the studied sample. ${ }^{43,44}$ This example emphasizes the necessity of establishing experimental protocols and dose limits for X-ray spectroscopy, in particular for high-valent metal complexes, to avoid X-ray induced sample damage.

\section{Dose-dependent reduction of $\mathrm{Mn}^{\mathrm{III}}(\mathrm{acac})_{3}$ in solution}

In Fig. 5 we combine the results from our least-squares fits of all spectra in one "dose plot". At a dose close to zero we observe that around $100 \%$ of $\mathrm{Mn}^{\mathrm{III}}(\mathrm{acac})_{3}$ are present in the sample and the amount of $\mathrm{Mn}^{\mathrm{III}}(\mathrm{acac})_{3}$ decreases gradually to around $35 \%$ when the average dose increases to around $3 \mathrm{MGy}$. We employ a least-squares fit of the exponential decay function $P(D)=P_{0} \cdot \exp (-k \cdot D)$, where $P$ is the relative amount of $\mathrm{Mn}^{\mathrm{III}}(\mathrm{acac})_{3}$ in the sample, $D$ denotes the

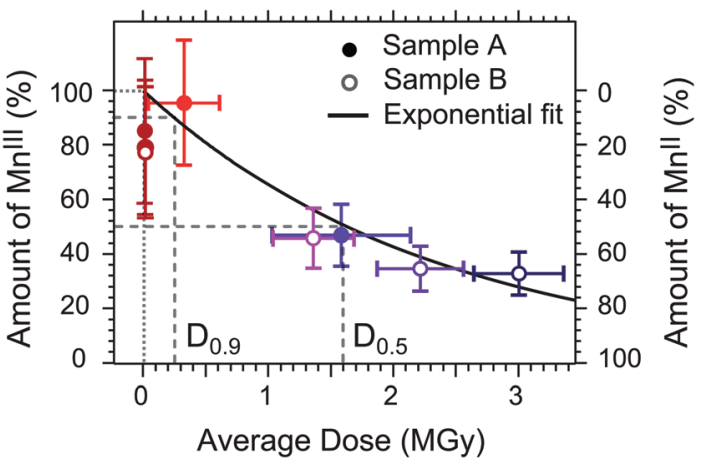

Fig. 5 Dose plot combining the experimental results from this work, depicting the portion of $\mathrm{Mn}^{\mathrm{III}}(\mathrm{acac})_{3}$ as a function of average absorbed $X$-ray dose (circles with error bars). Horizontal error bars reflect the uncertainty of the sample thickness and the range of doses surpassed during a scan (minimum-to-maximum values), vertical error bars reflect systematic uncertainties. The color code reflects that of the spectra in Fig. 3. Solid line: exponential decay model fitted with a decay constant of $k=(0.425 \pm 0.085) \times 10^{-7} \mathrm{~Gy}^{-1}$ with a half-damage dose of $D_{0.5}=1.6 \pm$ 0.4 MGy and a spectroscopically tolerable dose of $D_{0.9}=0.25 \pm 0.05$ MGy ( $90 \%$ of the sample intact).

average dose and $k$ is the exponential decay parameter in units of $\mathrm{Gy}^{-1}$. With this we assume a first-order reduction reaction as a function of dose similar to the analysis in ref. 21 and as further justified in the following section. The decay constant resulting from this fit is $k=(4.25 \pm 0.85) \times 10^{-7} \mathrm{~Gy}^{-1}$ (error bars are one standard deviation from the fit). The "half-damage" dose, $D_{0.5}$, is $1.6 \pm 0.4 \mathrm{MGy}$, where $50 \%$ of $\mathrm{Mn}^{\mathrm{III}}(\mathrm{acac})_{3}$ in the sample is reduced to $\mathrm{Mn}^{\mathrm{II}}$. As Mn L-edge spectra at this dose level are severely affected by X-ray induced sample damage (the high-dose spectrum in Fig. 2a represents the half-dose level), establishing a spectroscopically tolerable dose limit is useful. ${ }^{21}$ For example, at a conservative dose limit of $D_{0.99}=23 \pm 5 \mathrm{kGy}$, $99 \%$ of the sample is intact. The spectra recorded at flux setting 2 ("a", "b", "c" in Fig. 3) are affected by a dose smaller than this conservative limit and are hence unaffected by damage. Our analysis of the low-dose spectrum from Fig. $2 \mathrm{~b}$ and $4 \mathrm{a}$ shows that this spectrum is also almost unaffected by damage. The average dose assigned to this spectrum is close, for example, to the less conservative dose limit defined as $D_{0.9}=0.25 \pm$ 0.05 MGy (average dose) where $90 \%$ of the sample is intact. The good agreement of this spectrum with the damage-free spectrum of $\mathrm{Mn}^{\mathrm{III}}(\mathrm{acac})_{3}$ (Fig. 2b) validates the choice of the less conservative dose limit of $D_{0.9}$ here for spectroscopically tolerable dose in Mn L-edge XAS. We note that for transmissiondetected XAS of non-flowing solution samples this dose limit of $\sim 0.25 \mathrm{MGy}$ is reached within a fraction of a second at typical undulator beamlines, using a soft X-ray flux on the order of $10^{12}$ photons s $^{-1}$.

In the above analysis we assumed that diffusion-driven exchange of liquid sample with the sample reservoir is negligible. However, if a solution sample is scanned sequentially with an accumulated duration of up to $\sim 1 \mathrm{~h}$, taking into account these diffusion effects may be required when estimating the effective dose. Using the diffusion coefficient of $D \sim 4 \times 10^{-6} \mathrm{~cm}^{2} \mathrm{~s}^{-1}$ 
reported for $\mathrm{Mn}^{\mathrm{III}}(\mathrm{acac})_{3}$ in solution, ${ }^{35}$ we estimate that the effective dose of a probed sample volume can be up to one order of magnitude smaller than the average dose values determined above. The reason for this is the continuous, diffusion-driven mixing of irradiated sample in the probing region with nonirradiated sample from the sample reservoir. In turn, the dose limits of $D_{0.9} \sim 0.25 \mathrm{MGy}\left(D_{0.5} \sim 1.6 \mathrm{MGy}\right)$ reported here may be overestimated by up to one order of magnitude so that the same sample without diffusion-driven mixing could have dose limits on the order of $D_{0.9} \sim 0.03 \mathrm{MGy}\left(D_{0.5} \sim 0.2 \mathrm{MGy}\right)$.

\section{Mechanism for dose-dependent reduction}

As shown in Fig. 5, an exponential decay function describing how the damage varies with dose agrees well with the experimental data, and a possible rationale for these data is as follows. Most of the photons absorbed by the sample are absorbed by light atoms in the sample ( $\mathrm{H}, \mathrm{C}, \mathrm{O})$ and generate fast ("primary") Auger- and photo-electrons which scatter multiple times within the sample bulk. For a given sample volume, each absorption event generates a number of secondary electrons, proportional to the absorbed energy and thus to the dose absorbed by the sample volume. These electrons are the reactants driving the reduction of $\mathrm{Mn}^{\mathrm{III}}$ to $\mathrm{Mn}^{\mathrm{II}}$ as expressed by the simplified equation $\mathrm{Mn}^{\mathrm{III}}+$ $\mathrm{e}^{-} \rightarrow \mathrm{Mn}^{\mathrm{II}}$. This reaction is expected to follow a first order kinetic in time, described by an exponential decay as a function of time. The electrons are generated at low rates (at a dose of $\sim 1-10^{3} \mathrm{~Gy} \mathrm{~s}^{-1}$, corresponding to a dose of $\sim \mathrm{kGy}$ to $\sim$ MGy absorbed in $10 \mathrm{~min}$ ), presumably lower than the rate of the reduction reaction, which occurs in picoseconds. ${ }^{45}$ This would justify that the progress of this reaction is dependent on the dose rather than the time and hence also that the first order reaction is a function of dose, as applied to the fit in Fig. 5.

It is also important for understanding the reduction reaction to determine the chemical identity of the reduced $\mathrm{Mn}^{\mathrm{II}}$ species resulting from the reduction of $\mathrm{Mn}^{\mathrm{III}}$ (acac). Within the limitations of our fitting model, we extract a spectrum of the reduced $\mathrm{Mn}^{\mathrm{II}}$ species by subtracting from the high-dose spectrum (Fig. 4b) the undamaged spectrum of $\mathrm{Mn}^{\mathrm{III}}$ (acac) ${ }_{3}$ (Fig. 2b), scaled according to its contribution $(47 \%)$ at the given dose level. This difference spectrum of the reduced $\mathrm{Mn}^{\mathrm{II}}$ species is shown in Fig. 6 as spectrum "a" and we use it in the following to tentatively assess the chemical nature of the reduced species. The spectrum is compared to Mn L-edge XAS spectra calculated with the ab initio RAS approach for a series of Mn acetylacetonate complexes with different molecular geometries (see Methods section) and Mn oxidation states (Fig. 6). Spectra "b", "c" and "e" are comparable to those in ref. 15 and 23. All spectra were calculated with a smaller basis set but show no significant differences to the spectra in the references. The energy axis of the spectra is calibrated as previously, their relative energies are plotted as calculated.

We start with RAS spectrum "b", calculated for the optimized structure of $\mathrm{Mn}^{\mathrm{III}}(\mathrm{acac})_{3}$ with a central Jahn-Teller distorted, nearly octahedral $\mathrm{MnO}_{6}$ cluster (Fig. 6, top right). For the $\mathrm{Mn}^{\mathrm{III}}$ complex no good agreement is found in the shape of the $\mathrm{L}_{3}$-edge as compared to the spectrum of reduced $\mathrm{Mn}^{\mathrm{II}}$. When going from "b" to "c", changing the oxidation state from $\mathrm{Mn}^{\mathrm{III}}$ to $\mathrm{Mn}^{\mathrm{II}}$

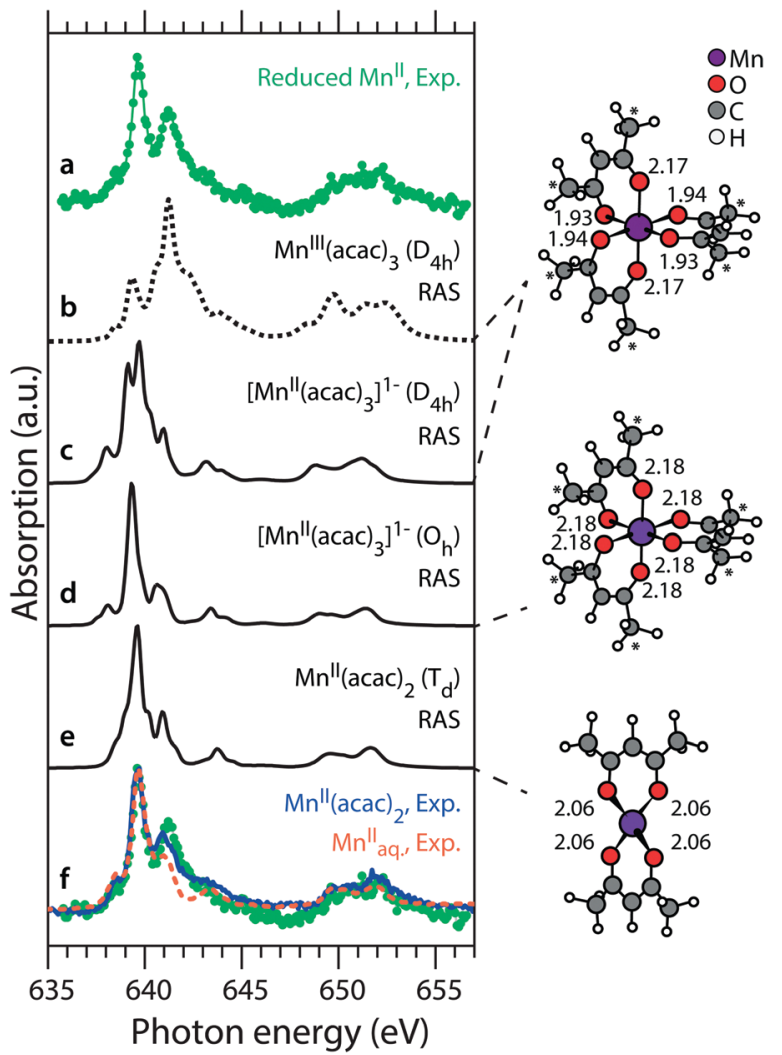

Fig. 6 Left: Spectrum of the reduced $M n^{\prime \prime}$ species (a), obtained from subtracting the fitted portion of $47 \%$ damage-free $\mathrm{Mn}^{\prime \prime \prime}(\mathrm{acac})_{3}$ from ref. 15 from the high-dose spectrum in Fig. $2 \mathrm{~b}$. This spectrum is compared to spectra from RAS calculations for different acetylacetonate complexes of $\mathrm{Mn}^{\text {III }}$ (b) and $\mathrm{Mn}^{\text {II }}$ ( $\mathrm{c}-\mathrm{e}$ ), with relative energies as calculated. In the bottom row (f) it is overlaid (gray) with experimental spectra of damagefree $\mathrm{Mn}^{\prime \prime}(\mathrm{acac})_{2}$ in solution of ethanol (solid blue) from ref. 15 and of $\mathrm{Mn}_{\mathrm{aq}}^{\prime \prime}$. (dashed orange) from ref. 39. Right: Molecular structures in the RAS calculations ( $\mathrm{Mn}-\mathrm{O}$ bond lengths in $\AA$ ).

(while keeping the molecular structure constant) clearly improves the similarity. This is observed as a spectral shift of the $\mathrm{L}_{3}$-edge maximum between $\mathrm{Mn}^{\mathrm{III}}$ and $\mathrm{Mn}^{\mathrm{II}}$ by $1.5 \mathrm{eV}$, consistent with previous studies. ${ }^{12,22,23}$ On this level of sensitivity, we note that the ability to predict the spectrum of a complex using ab initio RAS calculations is a powerful tool as it may indicate potential issues with X-ray induced sample damage in the experimental data. As compared to "c", spectrum "d" differs in that the molecular structure is optimized ("allowed to relax") for the oxidation state of $\mathrm{Mn}^{\mathrm{II}}$ (Fig. 6, middle right). This slightly improves the similarity of theoretical and experimental $\mathrm{L}_{3}$-edge shapes with respect to the reduced $\mathrm{Mn}^{\mathrm{II}}$ species. As a last step with RAS, with spectrum "e" we also compare the spectrum calculated for the optimized structure of $\mathrm{Mn}^{\mathrm{II}}$ (acac) $)_{2}$ with a central, tetrahedral $\mathrm{MnO}_{4}$ cluster (Fig. 6, bottom right). ${ }^{15,23}$ The agreement of spectral shapes improves, if at all, only slightly. We find that the spectrum calculations with RAS confirm the $\mathrm{Mn}^{\mathrm{II}}$ oxidation state of the reduced species, but predicted differences in spectra are not large enough to allow for assigning its molecular structure.

In row "f" of Fig. 6 we overlay spectrum "a" of the damage product (green) with the absorption spectrum of damage-free 
$\mathrm{Mn}^{\mathrm{II}}(\mathrm{acac})_{2}$ in solution (solid blue) ${ }^{15}$ and find comparably good agreement in shape and energy of most spectral features (except for some deviation in the peak at $641.6 \mathrm{eV}$ ). This could imply that the final product of X-ray induced sample damage is $\mathrm{Mn}^{\mathrm{II}}$ (acac) $)_{2}$ which has one acetylacetonate ligand less than the original $\mathrm{Mn}^{\mathrm{III}}(\mathrm{acac})_{3}$ complex. For comparison, we also show the spectrum of aqueous solution of ionic $\mathrm{Mn}^{\text {II }}$ (dashed orange) from ref. 39. This spectrum shows slightly less similarity to the spectrum of the reduced $\mathrm{Mn}^{\mathrm{II}}$ species than that of $\mathrm{Mn}^{\mathrm{II}}(\mathrm{acac})_{2}$, in particular with respect to the peak at $641.6 \mathrm{eV}$ and to the high-energy side of the $\mathrm{L}_{3}$-edge. This comparison could support a tentative, but not significant assignment of the reduction product to $\mathrm{Mn}^{\mathrm{II}}$ (acac) $)_{2}$. We note, however, that this assignment may be biased by the choice of our fit model (Fig. 4).

We summarize our analysis in a possible three- or four-step reaction mechanism, respectively, for the dose-dependent damage of $\mathrm{Mn}^{\mathrm{III}}(\mathrm{acac})_{3}$ in solution. First, an X-ray photon $(h \nu)$ is absorbed by an atom or molecule A, predominantly ( $\sim 90 \%$ and more) by the abundant solvent molecules $\left(\sim 10^{4} \mathrm{mM}\right.$ as compared to sample concentrations around $\sim 10^{2} \mathrm{mM}$ with respective absorption cross sections at the Mn L-edge of $\sim 10^{6}$ barns or $10^{-22} \mathrm{~m}^{2}$ for the solvent molecules, ${ }^{32,33}$ and up to $\sim 10^{7}$ barns or $10^{-21} \mathrm{~m}^{2}$ for the solute ${ }^{15}$ ), and a fast Auger- or photoelectron $\left(\mathrm{e}^{-}\right)$with a kinetic energy $E_{\text {kin }}$ is emitted from A.

$$
h \nu+\mathrm{A} \rightarrow \mathrm{A}^{+}+\mathrm{e}^{-}+E_{\text {kin }}
$$

Each of these fast, primary electrons scatters multiple times, each time transferring part of its kinetic energy to the scattering partners B (other atoms or molecules) creating a cascade of $\mathrm{N}$ Auger- and photoelectrons and $\mathrm{N}$ radicals $\mathrm{B}^{+}$.

$$
\mathrm{e}^{-}+E_{\text {kin }}+\mathrm{N} \cdot \mathrm{B} \rightarrow(\mathrm{N}+1) \cdot \mathrm{e}^{-}+\mathrm{N} \cdot \mathrm{B}^{+}
$$

The resulting $N+1$ electrons are slow as they have lost almost their entire kinetic energy. They can either recombine with their parent ions or migrate through the liquid sample (diffusion coefficient $\sim 5$ $\left.\times 10^{-5} \mathrm{~cm}^{2} \mathrm{~s}^{-1}\right)^{46}$ and react with intact $\mathrm{Mn}^{\mathrm{III}}(\mathrm{acac})_{3}$ molecules, thereby reducing it to $\left[\mathrm{Mn}^{\mathrm{II}}(\mathrm{acac})_{3}\right]^{1-}$ (since diffusion depends on temperature, the relative amounts of recombination and migration/ reduction events can also depend on temperature). ${ }^{3}$

$$
\mathrm{Mn}^{\mathrm{III}}(\text { acac })_{3}+\mathrm{e}^{-} \rightarrow\left[\mathrm{Mn}^{\mathrm{II}}(\text { acac })_{3}\right]^{1-}
$$

So far this reaction mechanism seems substantiated by the spectral comparison in Fig. 6 . The reduced molecule $\left[\mathrm{Mn}^{\mathrm{II}}(\mathrm{acac})_{3}\right]^{1-}$ may then possibly dissociate to

$$
\left[\mathrm{Mn}^{\mathrm{II}}(\mathrm{acac})_{3}\right]^{1-} \rightarrow \mathrm{Mn}^{\mathrm{II}}(\mathrm{acac})_{2}+(\text { acac })^{1-}
$$

where a potentially negatively charged acetylacetonate ligand could detach and be solvated by the structurally identical solvent. This may be supported by the slightly better but not significant spectral similarity of the reduced $\mathrm{Mn}^{\mathrm{II}}$ species with $\mathrm{Mn}^{\mathrm{II}}(\mathrm{acac})_{2}$ than with ionic $\mathrm{Mn}_{\mathrm{aq}}^{\text {II }}$ in the bottom row "f" of Fig. 6.

\section{Comparison to dose limits from literature}

The nature of how X-ray induced sample damage is reflected in Mn L-edge XAS, i.e. by local chemical changes leading to a reduced $\mathrm{Mn}^{\mathrm{II}}$ species, differs from how damage affects X-ray diffraction (XRD) approaches, where long-range structural changes of the protein crystal are, for example, reflected in a decreased diffraction intensity.

For the assessment of our results from this work, in Table 1 we now compare our half-damage dose limit, $D_{0.5} \sim 1.6 \mathrm{MGy}$ (with a potential overestimation by up to an order of magnitude, see above), to some half-damage dose-limits $D_{0.5}$ reported in literature (or dose-limits extracted numerically from published data). We note that these dose limits often vary by an order of magnitude, even for similar samples and within a single study. We therefore keep our discussion on the level of an order of magnitude. Following Table 1 from top to bottom, we first compare with dose-limits reported in X-ray diffraction and $\mathrm{X}$-ray spectroscopic studies with hard X-rays, and we then turn to spectroscopic results with soft X-rays. Dose-limits for hard and soft X-rays are herein compared directly, which is justified as for a given dose value the concentration of slow electrons in the probed sample volume, and thus the relative amount of damaged sample, is largely independent from the X-ray energy (see also definition above of the X-ray dose).

Typical $D_{0.5}$ dose limits for the loss of diffraction signal and thus for long-range structural damage in X-ray diffraction studies of protein crystals with hard X-rays are reported between 0.4 and $43 \mathrm{MGy}^{1,2,7,8}$ These studies can be divided into two groups, first with frozen samples at cryogenic temperatures (dose limits $D_{0.5}$ between 12 and $\left.43 \mathrm{MGy}\right)^{1,2,7}$ and, second, with solution samples at room temperature (dose limits $D_{0.5}$ between 0.4 and $1.8 \mathrm{MGy}){ }^{8}$ The well-known trend that dose limits are lower at room temperature than at cryogenic temperatures, may be explained with decreased (temperature-dependent) diffusion of electrons and radicals (electron-gain and electron-loss centers) ${ }^{3}$ driving the sample damage. ${ }^{47}$ As compared to long-range structural changes in the crystal lattice relevant for the loss of X-ray diffraction signal, dose-dependent effects of local chemical changes, e.g. the reduction of functional sites in (metallo-) proteins, were shown to occur already at lower doses. High-resolution X-ray diffraction experiments show, for example, that the local trapping of radicals and local reduction processes occur at doses around $D_{0.5} \sim$ 0.2-0.4 MGy (here at cryogenic temperatures) and thus appear to precede the loss of diffractivity. ${ }^{6}$

Local chemical changes, in particular the reduction of highvalent transition metal sites, are sensitively probed with X-ray and UV-vis spectroscopic studies of metalloproteins irradiated with hard X-rays. ${ }^{18,19,48}$ In those studies, the dose-dependent reduction of high-valent transition metal sites was observed to occur at dose-limits $D_{0.5}$ between 0.2 and $10 \mathrm{MGy}$ at cryogenic temperatures, ${ }^{18,48}$ and between 0.2 and $0.6 \mathrm{MGy}$ at room temperature. ${ }^{19}$ We find that within the accuracy level of our discussion (one order of magnitude) both ranges of dose-limits, in particular for the reduction of high-valent $\mathrm{Mn}^{\mathrm{III}}$ and $\mathrm{Mn}^{\mathrm{IV}}$ sites in PS II, ${ }^{18,19}$ are consistent with the dose-limit $D_{0.5}$ of 1.6 MGy found here for the reduction of $\mathrm{Mn}^{\mathrm{III}}(\mathrm{acac})_{3}$ in room temperature solution.

Among the few studies of dose-dependent sample damage by soft X-rays, we are only aware of data from iron complexes in the solid phase where dose-limits $D_{0.5}$ with large spreads were 
Table 1 Comparison of dose limits for X-ray induced sample damage in terms of half-damage doses $D_{0.5}$ and spectroscopically tolerable doses $D_{0.9}$ (where $90 \%$ of the sample is intact) from this work and published results using X-ray diffraction (XRD) methods, and X-ray absorption (XAS) and emission spectroscopies (XES)

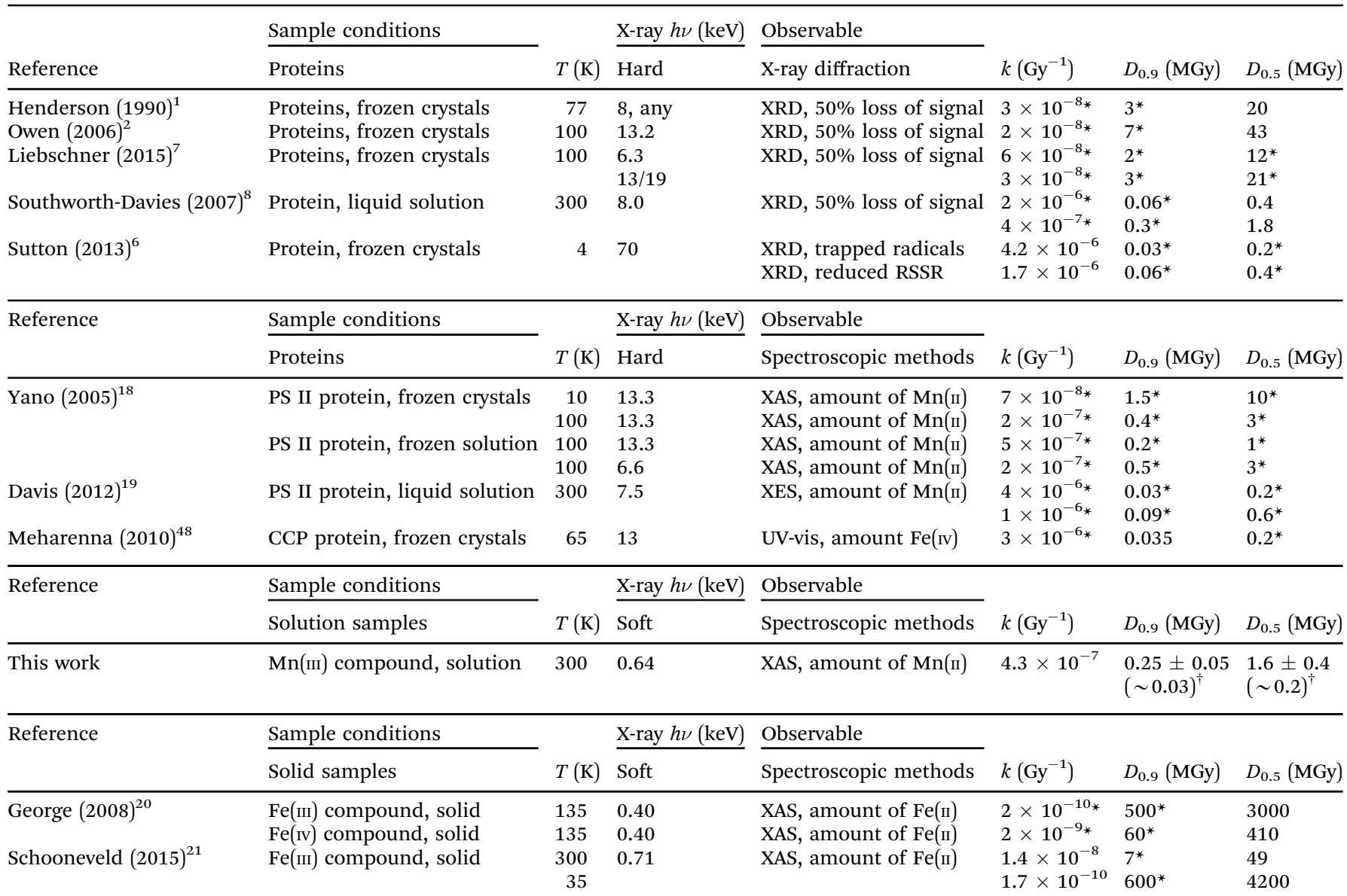

Values marked with * were calculated from values and fit-curves given in the references, assuming a single exponential decay function. Values marked with $\dagger$ are estimated lower limits, including diffusion driven sample exchange with the sample reservoir.

reported, ranging from 49 to $4200 \mathrm{MGy}$, even for the same compounds and within a single study. ${ }^{20,21}$ These dose limits reported for the reduction of $\mathrm{Fe}^{\mathrm{III}}$ and $\mathrm{Fe}^{\mathrm{IV}}$ in the solid phase are two to four orders of magnitude larger than the limits determined here for the reduction of $\mathrm{Mn}^{\mathrm{III}}$ in solution. At this point, however, it remains an open question whether the nature and the oxidation state of the metal center (Fe or Mn), the sample temperature or the phase of the sample (solid vs. solution) determines these differences in the sensitivity to X-ray induced sample damage. We speculate that the apparent higher sensitivity of the solution sample studied here is due to a facilitated diffusion of electrons and radicals in solution samples as compared to the solid samples, where charge migration may be limited to tunneling effects. This decreased mobility of electrons and radicals in solid samples could explain an increased role of electron-ion recombination after the primary ionization event, counteracting diffusion-driven sample damage and leading to increased doselimits as compared to solution samples. Comparable studies of high-valent meal complexes in the solid and the liquid phase and at different temperatures could further explain the above differences in sensitivity to dose-dependent sample damage.
The dose limits reported here for the reduction of $\mathrm{Mn}^{\mathrm{III}}$ in solution and at room temperature can be used to assess other experimental approaches and to validate other spectroscopic results for the influence of sample damage. In particular, we can validate our damage-free L-edge absorption spectra of $\mathrm{Mn}^{\mathrm{III}}(\mathrm{acac})_{3}$ in solution that were acquired with different types of fast-flowing liquid jets. For transmission-detected Mn L-edge XAS of $\mathrm{Mn}^{\mathrm{III}}$ (acac) $)_{3}$ using a transmission flatjet, we estimated an average dose of around $20 \mathrm{~Gy},{ }^{15}$ and for our results from partial fluorescence-yield (PFY) detected XAS we estimated an average dose on the order of $5 \mathrm{kGy} .{ }^{23}$ With the results from this work, we can therefore estimate amounts of less than $1 \%$ of damaged metal centers in those studies and validate the results as free from sample damage.

We also compare our current results with the data collected with femtosecond soft X-ray pulses from X-ray free electron lasers (XFEL), ${ }^{22}$ in which we collected PFY-detected Mn L-edge XAS of high-valent $\mathrm{Mn}^{\mathrm{III}}$ and $\mathrm{Mn}^{\mathrm{IV}}$ complexes in solution and at room temperature. Based on spectral comparisons we concluded there that the spectra are free of X-ray induced sample damage. Each sample volume probed by the intense, $100 \mathrm{fs}$ soft X-ray XFEL 
pulses was estimated to absorb an average dose of around 2-4 MGy. ${ }^{22}$ These dose values are much larger than the spectroscopically tolerable dose limit of $\sim 0.3 \mathrm{MGy}\left(D_{0.9}\right)$ determined here for $\mathrm{Mn}^{\mathrm{III}}(\mathrm{acac})_{3}$ in solution, using soft X-rays from a storagering synchrotron radiation source; one would expect sample damage on the order of $50 \%$ for comparable experiments at a synchrotron radiation sources. The fact that no X-ray induced reduction of Mn was observed in the XFEL data implies that, using an XFEL, the spectral information is probed on ultrafast time scales (100 femtosecond) and outruns the effects of diffusion-driven (dose-dependent) sample-damage that occur on the order of picoseconds. ${ }^{45}$

\section{Conclusions}

In this paper, we analyze dose-dependent X-ray induced sample damage to $\mathrm{Mn}^{\mathrm{III}}(\mathrm{acac})_{3}$ in solution and at room temperature for the soft X-ray energy range. We employ X-ray absorption spectroscopy at the Mn L-edge to quantify the amount of damaged sample. Spectra measured at an average dose on the order of $\sim 0.3$ MGy are nearly identical with damage-free spectra published previously. For a larger dose we observe increasing spectral contributions from a reduced $\mathrm{Mn}^{\mathrm{II}}$ species resulting from the X-ray induced reduction of $\mathrm{Mn}^{\mathrm{III}}(\mathrm{acac})_{3}$. On the basis of calculated spectra from the $a b$ initio restricted active space (RAS) approach and comparison to damage-free experimental spectra of $\mathrm{Mn}^{\mathrm{II}}(\mathrm{acac})_{2}$ and $\mathrm{Mn}_{\mathrm{aq}}^{\mathrm{II}}$. in solution, we discuss a possible mechanism for the X-ray induced reduction of $\mathrm{Mn}^{\mathrm{III}}(\mathrm{acac})_{3}$ in solution. We model the reduction reaction with a singleexponential dose-dependence and quantify an amount of $50 \%$ sample damage at $1.6 \pm 0.4 \mathrm{MGy}$. We establish a spectroscopically tolerable dose limit of $0.25 \pm 0.05 \mathrm{MGy}$, where $90 \%$ of the sample is intact. We discuss that diffusion-driven mixing of the liquid sample may cause a systematic overestimation of the effective dose-limit in this analysis by up to one order of magnitude. The dose limit reported here for the X-ray induced reduction of $\mathrm{Mn}^{\mathrm{III}}(\mathrm{acac})_{3}$ in room temperature solution by soft $\mathrm{X}$-rays is hence around one order of magnitude smaller than the dose-limits typically used to delimit the loss of X-ray diffraction intensity in protein crystallography at cryogenic temperatures, but is consistent with dose-limits reported for the reduction of high-valent metal sites in metalloproteins, such as the oxygen evolving Mn complex in photosystem II, by hard X-rays. Comparison to other available studies with soft X-rays reveals an unexplained discrepancy by two to four orders of magnitude in dose between the experimental dose limits determined here for solution samples and those reported for iron complexes in the solid phase. Still, the observed photoreduction is expected to occur also in other high-valent transition metal complexes in solution. Using the dose limits determined here we validate other experimental approaches that promise damage-free soft X-ray absorption spectra of solution samples, relevant for studying catalysts and metalloproteins under ambient conditions. These approaches comprise fast-flowing liquid jets at synchrotron radiation sources and femtosecond pulses from X-ray free electron lasers, which outrun the time-scales of (dose-dependent) diffusion-driven sample damage.

\section{Author contributions}

Conceived the experiment: M. K., J. K., J. Y., V. Y., Ph. W. Designed the experiment: M. K., Ph. W. Prepared the samples: M. K. Carried out the experiment: M. K. Analyzed the data: M. K., under the supervision of Ph. W. Carried out $a b$ initio restricted active space calculations: M. G., E. K., M. L. Wrote the paper: M. K. with contribution from all authors.

\section{Conflicts of interest}

There are no conflicts of interest to declare.

\section{Acknowledgements}

We gratefully acknowledge the continuous support by the BESSY II staff and we thank HZB for the allocation of synchrotron radiation beamtime. We thank Simon Schreck (HZB) for advising us on the transmission NEXAFS setup and Christian Weniger (HZB) and Brian Kennedy (HZB) for the preparation of the transmission membranes. We acknowledge financial support from Human Frontiers Science Program (RGP0063/2013) (Ph. W., J. Y.), the Swedish Research Council (Grant No. 2012-3924), and the Knut and Alice Wallenberg Foundation (Grant No. KAW2013.0020). The computations were performed on resources provided by SNIC through Uppsala Multidisciplinary Center for Advanced Computational Science (UPPMAX) under project snic2016-1-464 and National Supercomputer Centre at Linköping University (Triolith) under project snic2016-1-508. Parts of this research are supported by the Director, Office of Science, Office of Basic Energy Sciences, Division of Chemical Sciences, Geosciences, and Biosciences of the Department of Energy under contract DE-AC02-05CH11231 (J. Y., V. K. Y.), and by the NIH Grants GM110501 (J. Y.), GM126289 (J. K.) and GM55302 (V. K. Y).

\section{References}

1 R. Henderson, Proc. Biol. Sci., 1990, 241, 6-8.

2 R. L. Owen, E. Rudino-Pinera and E. F. Garman, Proc. Natl. Acad. Sci. U. S. A., 2006, 103, 4912-4917.

3 P. O'Neill, D. L. Stevens and E. F. Garman, J. Synchrotron Radiat., 2002, 9, 329-332.

4 E. F. Garman, Acta Crystallogr., Sect. D: Biol. Crystallogr., 2010, 66, 339-351.

5 M. Weik, R. B. G. Ravelli, G. Kryger, S. McSweeney, M. L. Raves, M. Harel, P. Gros, I. Silman, J. Kroon and J. L. Sussman, Proc. Natl. Acad. Sci. U. S. A., 2000, 97, 623.

6 K. A. Sutton, P. J. Black, K. R. Mercer, E. F. Garman, R. L. Owen, E. H. Snell and W. A. Bernhard, Acta Crystallogr., Sect. D: Biol. Crystallogr., 2013, 69, 2381-2394.

7 D. Liebschner, G. Rosenbaum, M. Dauter and Z. Dauter, Acta Crystallogr., Sect. D: Biol. Crystallogr., 2015, 71, 772-778. 
8 R. J. Southworth-Davies, M. A. Medina, I. Carmichael and E. F. Garman, Structure, 2007, 15, 1531-1541.

9 P. Glatzel and U. Bergmann, Coord. Chem. Rev., 2005, 249, 65-95.

10 U. Bergmann and P. Glatzel, Photosynth. Res., 2009, 102, 255-266.

11 M. A. Beckwith, M. Roemelt, M. N. Collomb, C. DuBoc, T. C. Weng, U. Bergmann, P. Glatzel, F. Neese and S. DeBeer, Inorg. Chem., 2011, 50, 8397-8409.

12 S. P. Cramer, F. M. F. DeGroot, Y. Ma, C. T. Chen, F. Sette, C. A. Kipke, D. M. Eichhorn, M. K. Chan and W. H. Armstrong, J. Am. Chem. Soc., 1991, 113, 7937-7940.

13 E. C. Wasinger, F. M. F. De Groot, B. Hedman, K. O. Hodgson and E. I. Solomon, J. Am. Chem. Soc., 2003, 125, 12894-12906.

14 J. K. Kowalska, B. Nayyar, J. A. Rees, C. E. Schiewer, S. C. Lee, J. A. Kovacs, F. Meyer, T. Weyhermüller, E. Otero and S. DeBeer, Inorg. Chem., 2017, 56, 8147-8158.

15 M. Kubin, M. Guo, M. Ekimova, M. L. Baker, T. Kroll, E. Källman, J. Kern, V. K. Yachandra, J. Yano, E. T. J. Nibbering, M. Lundberg and P. Wernet, Inorg. Chem., 2018, 57, 5449-5462.

16 M. Nagasaka, H. Yuzawa, T. Horigome, A. P. Hitchcock and N. Kosugi, J. Phys. Chem. C, 2013, 117, 16343-16348.

17 M. Risch, K. A. Stoerzinger, B. Han, T. Z. Regier, D. Peak, S. Y. Sayed, C. Wei, Z. Xu and Y. Shao-Horn, J. Phys. Chem. C, 2017, 121, 17682-17692.

18 J. Yano, J. Kern, K. D. Irrgang, M. J. Latimer, U. Bergmann, P. Glatzel, Y. Pushkar, J. Biesiadka, B. Loll, K. Sauer, J. Messinger, A. Zouni and V. K. Yachandra, Proc. Natl. Acad. Sci. U. S. A., 2005, 102, 12047-12052.

19 K. M. Davis, B. A. Mattern, J. I. Pacold, T. Zakharova, D. Brewe, I. Kosheleva, R. W. Henning, T. J. Graber, S. M. Heald, G. T. Seidler and Y. Pushkar, J. Phys. Lett., 2012, 3, 1858-1864.

20 S. J. George, J. Fu, Y. Guo, O. B. Drury, S. Friedrich, T. Rauchfuss, P. I. Volkers, J. C. Peters, V. Scott, S. D. Brown, C. M. Thomas and S. P. Cramer, Inorg. Chim. Acta, 2008, 361, 1157-1165.

21 M. M. van Schooneveld and S. DeBeer, J. Electron Spectrosc. Relat. Phenom., 2015, 198, 31-56.

22 M. Kubin, J. Kern, S. Gul, T. Kroll, R. Chatterjee, H. Löchel, F. D. Fuller, R. G. Sierra, W. Quevedo, C. Weniger, J. Rehanek, A. Firsov, H. Laksmono, C. Weninger, R. Alonso-Mori, D. L. Nordlund, B. Lassalle-Kaiser, J. M. Glownia, J. Krzywinski, S. Moeller, J. J. Turner, M. P. Minitti, G. L. Dakovski, S. Koroidov, A. Kawde, J. S. Kanady, E. Y. Tsui, S. Suseno, Z. Han, E. Hill, T. Taguchi, A. S. Borovik, T. Agapie, J. Messinger, A. Erko, A. Föhlisch, U. Bergmann, R. Mitzner, V. K. Yachandra, J. Yano and P. Wernet, Struct. Dyn., 2017, 4, 054307.

23 M. Kubin, M. Guo, T. Kroll, H. Löchel, E. Källman, M. L. Baker, R. Mitzner, S. Gul, J. Kern, A. Föhlisch, A. Erko, U. Bergmann, V. Yachandra, J. Yano, M. Lundberg and P. Wernet, 2018, submitted.

24 I. Josefsson, K. Kunnus, S. Schreck, A. Föhlisch, F. de Groot, P. Wernet and M. Odelius, J. Phys. Lett., 2012, 3, 3565-3570.

25 R. V. Pinjari, M. G. Delcey, M. Guo, M. Odelius and M. Lundberg, J. Chem. Phys., 2014, 141, 124116.

26 P. Å. Malmqvist, B. O. Roos and B. Schimmelpfennig, Chem. Phys. Lett., 2002, 357, 230-240.
27 P. Å. Malmqvist, K. Pierloot, A. R. M. Shahi, C. J. Cramer and L. Gagliardi, J. Chem. Phys., 2008, 128, 204109.

28 M. Preuße, S. I. Bokarev, S. G. Aziz and O. Kühn, Struct. Dyn., 2016, 3, 062601.

29 S. I. Bokarev, M. Khan, M. K. Abdel-Latif, J. Xiao, R. Hilal, S. G. Aziz, E. F. Aziz and O. Kühn, J. Phys. Chem. C, 2015, 119, 19192-19200.

30 S. Schreck, G. Gavrila, C. Weniger and P. Wernet, Rev. Sci. Instrum., 2011, 82, 103101.

31 P. S. Miedema, W. Quevedo and M. Fondell, Journal of largescale research facilities JLSRF, 2016, 2, 70.

32 B. L. Henke, E. M. Gullikson and J. C. Davis, At. Data Nucl. Data Tables, 1993, 54, 181-342.

33 CXRO, Center for X-ray Optics, X-ray Database, http://henke. lbl.gov/optical_constants/, accessed 06/01/2017, 2017.

34 H. C. Berg, Random walks in biology, Princeton University Press, 1993.

35 A. E. S. Sleightholme, A. A. Shinkle, Q. Liu, Y. Li, C. W. Monroe and L. T. Thompson, J. Power Sources, 2011, 196, 5742-5745.

36 F. Aquilante, L. De Vico, N. Ferre, G. Ghigo, P. A. Malmqvist, P. Neogrady, T. B. Pedersen, M. Pitonak, M. Reiher, B. O. Roos, L. Serrano-Andres, M. Urban, V. Veryazov and R. Lindh, J. Comput. Chem., 2010, 31, 224-247.

37 R. V. Pinjari, M. G. Delcey, M. Guo, M. Odelius and M. Lundberg, J. Comput. Chem., 2016, 37, 477-486.

38 M. Ohno and G. A. van Riessen, J. Electron Spectrosc. Relat. Phenom., 2003, 128, 1-31.

39 R. Mitzner, J. Rehanek, J. Kern, S. Gul, J. Hattne, T. Taguchi, R. Alonso-Mori, R. Tran, C. Weniger, H. Schröder, W. Quevedo, H. Laksmono, R. G. Sierra, G. Han, B. Lassalle-Kaiser, S. Koroidov, K. Kubicek, S. Schreck, K. Kunnus, M. Brzhezinskaya, A. Firsov, M. P. Minitti, J. J. Turner, S. Moeller, N. K. Sauter, M. J. Bogan, D. Nordlund, W. F. Schlotter, J. Messinger, A. Borovik, S. Techert, F. M. F. de Groot, A. Föhlisch, A. Erko, U. Bergmann, V. K. Yachandra, P. Wernet and J. Yano, J. Phys. Lett., 2013, 4, 3641-3647.

40 M. Risch, K. A. Stoerzinger, T. Z. Regier, D. Peak, S. Y. Sayed and Y. Shao-Horn, J. Phys. Chem. C, 2015, 119, 18903-18910.

41 Cross sections from personal communication by S. Schreck and Ph. Wernet, Helmholtz-Zentrum Berlin, Germany, 2018.

42 M. M. Grush, Y. Muramatsu, J. H. Underwood, E. M. Gullikson, D. L. Ederer, R. C. C. Perera and T. A. Callcott, J. Electron Spectrosc. Relat. Phenom., 1998, 92, 225-229.

43 S. Carlotto, M. Sambi, A. Vittadini and M. Casarin, Polyhedron, 2017, 135, 216-223.

44 S. Carlotto, L. Floreano, A. Cossaro, M. Dominguez, M. Rancan, M. Sambi and M. Casarin, Phys. Chem. Chem. Phys., 2017, 19, 24840-24854.

45 K. M. Davis, I. Kosheleva, R. W. Henning, G. T. Seidler and Y. Pushkar, J. Phys. Chem. B, 2013, 117, 9161-9169.

46 G. V. Buxton, C. L. Greenstock, W. P. Helman and A. B. Ross, J. Phys. Chem. Ref. Data, 1988, 17, 513-886.

47 E. Garman, Curr. Opin. Struct. Biol., 2003, 13, 545-551.

48 Y. T. Meharenna, T. Doukov, H. Li, S. M. Soltis and T. L. Poulos, Biochemistry, 2010, 49, 2984-2986. 